\title{
Aspirin but not vitamin E prevented cardiovascular events in patients at risk
}

\author{
Collaborative Group of the Primary Prevention Project (PPP). Low-dose aspirin and vitamin E in people at cardiovascular \\ risk: a randomised trial in general practice. Lancet 2001 Jan 13;357:89-95.
}

\section{QUESTION: In patients with $\geqslant 1$ cardiovascular risk factor but no history of cardiovascular disease, how effective is treatment with aspirin and vitamin $E$ in preventing cardiovascular events?}

\section{Design}

Randomised (allocation concealed*), unblinded,* $2 \times 2$ factorial trial with mean 3.6 years of follow up.

\section{Setting}

315 general practices and 15 hospital hypertension units in Italy.

\section{Patients}

4495 patients who were $\geqslant 50$ years of age (mean age 64 $y, 58 \%$ women) and had $\geqslant 1$ major cardiovascular risk factor: age $\geqslant 65$ years, hypertension, hypercholesterolaemia, diabetes mellitus, obesity, and family history of myocardial infarction (MI) before 55 years of age in $\geqslant 1$ parent or sibling. Exclusion criteria were treatment with antiplatelet drugs, chronic use of anti-inflammatory agents or anticoagulants, contraindication to aspirin, disease with a poor short term prognosis, or psychological or logistic problems known to affect compliance. Follow up was $92 \%$.

Sources of funding:

Medical Department of Bayer Italy; aspirin preparation supplied by

Bayer; vitamin $E$ capsules supplied by Bracco SpA.

For correspondence: Dr M C Roncaglioni Istituto di Ricerche

Farmacologiche "Mario

Negri," Via Eritrea 62,

20157 Milan, Italy.

Fax +3902

39001916 .

A modified version of

this abstract also

appears in

Evidence-Based

Nursing.

\section{Intervention}

Patients were allocated to aspirin, one $100 \mathrm{mg}$ enteric coated tablet per day $(n=2226)$, or to no aspirin $(\mathrm{n}=2269)$, and to vitamin $\mathrm{E}$, one $300 \mathrm{mg}$ (300 IU) synthetic $\alpha$ tocopherol capsule $(n=2231)$, or to no vita$\min \mathrm{E}(\mathrm{n}=2264)$. calculated from data in article.

\section{Main outcome measures}

The primary outcome was a combined end point of cardiovascular death, non-fatal MI, and non-fatal stroke. Secondary outcomes were cardiovascular deaths, total deaths, and total cardiovascular events.

\section{Main results}

Analysis was by intention to treat. The trial was stopped early because evidence from 2 large trials indicated a benefit of aspirin in cardiovascular primary prevention that was borne out by the planned interim analysis in this trial. Patients who received aspirin had a significantly reduced risk for cardiovascular death $(\mathrm{p}=0.049)$ and total cardiovascular events $(\mathrm{p}=0.014)$, but no statistically significant difference existed between groups for the main combined end point or for any other outcome (table). Patients who received vitamin E did not show reduced risk for any outcomes except for the incidence of peripheral artery disease $(0.7 \% v 1.3 \%, \mathrm{p}=0.043)$.

\section{Conclusion}

In patients with cardiovascular risk but no history of cardiovascular disease, aspirin but not vitamin E prevented cardiovascular events.

*See glossary.

Aspirin $v$ no aspirin and vitamin Ev no vitamin E for patients with major cardiovascular risk factors $\dagger$

\begin{tabular}{llllll} 
Outcomes at mean of 3.6 years & Comparison & Event rates & RRR (95\% Cl) & NNT (Cl) \\
Combined end point & Aspirin $v$ no aspirin & $2.0 \% v 2.8 \%$ & $29 \%(-4$ to 52$)$ & Not significant \\
\hline Cardiovascular death & Aspirin $v$ no aspirin & $0.8 \% v 1.4 \%$ & $44 \%(1$ to 69$)$ & $166(81$ to 62500$)$ \\
\hline Total cardiovascular events & Aspirin $v$ no aspirin & $6.3 \% v 8.2 \%$ & $23 \%(5$ to 38$)$ & $53(30$ to 258$)$ \\
\hline Combined end point & & & RRI (CI) & NNH \\
\hline
\end{tabular}

†Combined end point = cardiovascular death, non-fatal myocardial infarction, and non-fatal stroke. Abbreviations defined in glossary; RRR, RRI, NNT, NNH, and Cl

\section{COMMENTARY}

The PPP trial substantially strengthens the existing evidence supporting the use of aspirin to prevent cardiovascular events. The most important feature of this trial is its study design. In contrast to previous prevention trials with aspirin, the PPP trial enrolled a broad based patient population. The inclusion criteria were liberal; patients were enrolled from community based practices, and $>50 \%$ of the enrolled patients were women. Previous prevention trials enrolled men or higher risk patients. Patients were eligible for the PPP trial simply by being $\geqslant 65$ years of age or obese (body mass index $>30 \mathrm{~kg} / \mathrm{m}^{2}$ ).

As in other recently published clinical trials, ${ }^{1}$ ingestion of vitamin $\mathrm{E}$ failed to provide any benefit in preventing cardiovascular events. The potential benefit of vitamin $\mathrm{E}$ is either very small or requires a longer period of ingestion than can be practically shown with a clinical trial.

In summary, low doses (80-100 mg) of enteric coated aspirin substantially lower the risk for cardiovascular events. In the absence of uncontrolled hypertension or other contraindications, practising physicians should recommend aspirin for their patients who are $\geqslant 65$ years of age or those with other known cardiovascular risk factors. The addition of vitamin $\mathrm{E}$ cannot be firmly recommended on the basis of the available evidence.

Robert Gluckman, MD Providence-St. Vincent Medical Center Portland, Oregon, USA

1 Yusuf S, Dagenais G, Pogue J, et al. Vitamin E supplementation and cardiovascular events in high-risk patients. The heart outcomes prevention evaluation study investigators. N Engl J Med 2000;342:154-60. 